Supporting Information

\title{
Storage of Lithium Metal: The Role of the Native Passivation Layer for the Anode Interface Resistance in Solid State Batteries
}

\author{
Svenja-K. Otto a, Till Fuchs a,b, Yannik Moryson a,b, Christian Lerch a, Boris Mogwitz a \\ Joachim Sann ${ }^{\text {a }}$, Jürgen Janek ${ }^{\mathrm{a}, \mathrm{b}} *$ and Anja Henss ${ }^{\mathrm{a}, \mathrm{b}} * *$ \\ ${ }^{a}$ Institute of Physical Chemistry, Justus-Liebig-Universität Giessen, \\ Heinrich-Buff-Ring 17, D-35392 Giessen, Germany \\ ${ }^{b}$ Center for Materials Research (ZfM), Justus-Liebig-Universität Giessen, \\ Heinrich-Buff-Ring 16, D-35392 Giessen, Germany \\ *E-Mail: juergen.janek@phys.chemie.uni-giessen.de \\ **E-Mail: anja.henss@ @ phys.chemie.uni-giessen.de
}

\section{This PDF file includes:}

SI 1: Overview of all samples

SI 2: Quantification of passivation layer compounds from XPS depth profiling

SI 3: Impact of different contamination levels in gloveboxes on lithium foil aging

SI 4: Impact of different storage conditions in gloveboxes on lithium foil aging

SI 5: Ideal lithium electrodes

SI 6: Representative Nyquist Plots

SI 7: Cryo FIB-SEM for interface visualization

SI 8: Theory about the reactivity of lithium toward atmospheric gases

SI 9: Pilling-Bedworth ratio

SI 10: Photo of stored lithium foil

SI 11: Reactivity of unprotected lithium surfaces toward atmospheric gases

SI 12: Reactivity of unprotected lithium surfaces in gloveboxes with and without nitrogen filter 


\section{SI 1: Overview of all samples}

Table S1: Overview of all samples which were stored in gloveboxes: glovebox $1-p\left(\mathrm{H}_{2} \mathrm{O}\right.$ and $\left.\mathrm{O}_{2}\right) / p$ of about 1 ppm and variations up to 10 ppm), glovebox $2-p\left(\mathrm{H}_{2} \mathrm{O}\right.$ and $\left.\mathrm{O}_{2}\right) / \mathrm{p}<0.1 \mathrm{ppm}$ and variations of up to 1 ppm and glovebox $3-p\left(\mathrm{H}_{2} \mathrm{O}\right.$ and $\left.\mathrm{O}_{2}\right) / p<0.1 \mathrm{ppm}$ and variations of up to $3 \mathrm{ppm}, \mathrm{p}\left(\mathrm{N}_{2}\right) / \mathrm{p}$ about $1 \mathrm{ppm}$.

\begin{tabular}{|c|c|c|c|c|}
\hline Sample type & Glovebox & Storage condition & Storage time / weeks & Data in Figure(s) \\
\hline Lithium foil & 1 & Closed plastic boxes & $2,5,10$ & $\begin{array}{l}1,2,5, \mathrm{~S} 2, \mathrm{~S} 3, \mathrm{~S} 4, \\
\mathrm{~S} 8\end{array}$ \\
\hline Lithium foil & 1 & Original transport package & Reference $(0)$ & $1,2, \mathrm{~S} 2, \mathrm{~S} 4, \mathrm{~S} 8$ \\
\hline Lithium foil & 2 & Closed plastic boxes & $2,5,10$ & $2, \mathrm{~S} 3$ \\
\hline Lithium foil & 2 & Original transport package & Reference $(0)$ & 2 \\
\hline Lithium foil & 1 & Closed plastic boxes & 5,20 & 3 \\
\hline Lithium foil & 1 & $\begin{array}{l}\text { Closed plastic boxes }+ \\
\text { pouch }\end{array}$ & 5 & S4 \\
\hline Lithium foil & 1 & Open boxes & 5 & S4 \\
\hline $\begin{array}{l}\text { Sliced } \\
\text { lithium rod }\end{array}$ & 1 & Closed plastic boxes & 5 & S10 \\
\hline $\begin{array}{l}\text { Sliced } \\
\text { lithium rod }\end{array}$ & 3 & Closed plastic boxes & 5 & S10 \\
\hline
\end{tabular}

Table S2: Overview of all samples which were exposed to pure gases.

\begin{tabular}{|l|l|l|l|l|}
\hline Sample type & Treatment & Conditions & Time & Data in Figure(s) \\
\hline Lithium foil & Gas exposure & $\begin{array}{l}100 \text { sccm of dried } \mathrm{N}_{2}, \mathrm{O}_{2} \text { and } \mathrm{CO}_{2}, \\
\mathrm{H}_{2} \mathrm{O} \text { with Ar as carrier gas }\end{array}$ & $22 \mathrm{~h}$ & 4 \\
\hline $\begin{array}{l}\text { Sliced } \\
\text { lithium rod }\end{array}$ & Gas exposure & $\begin{array}{l}100 \text { sccm of dried } \mathrm{N}_{2}, \mathrm{O}_{2} \text { and } \mathrm{CO}_{2}, \\
\mathrm{H}_{2} \mathrm{O} \text { with Ar as carrier gas }\end{array}$ & $22 \mathrm{~h}$ & $\mathrm{~S} 9$ \\
\hline
\end{tabular}

SI 2: Quantification of passivation layer compounds from XPS depth profiling
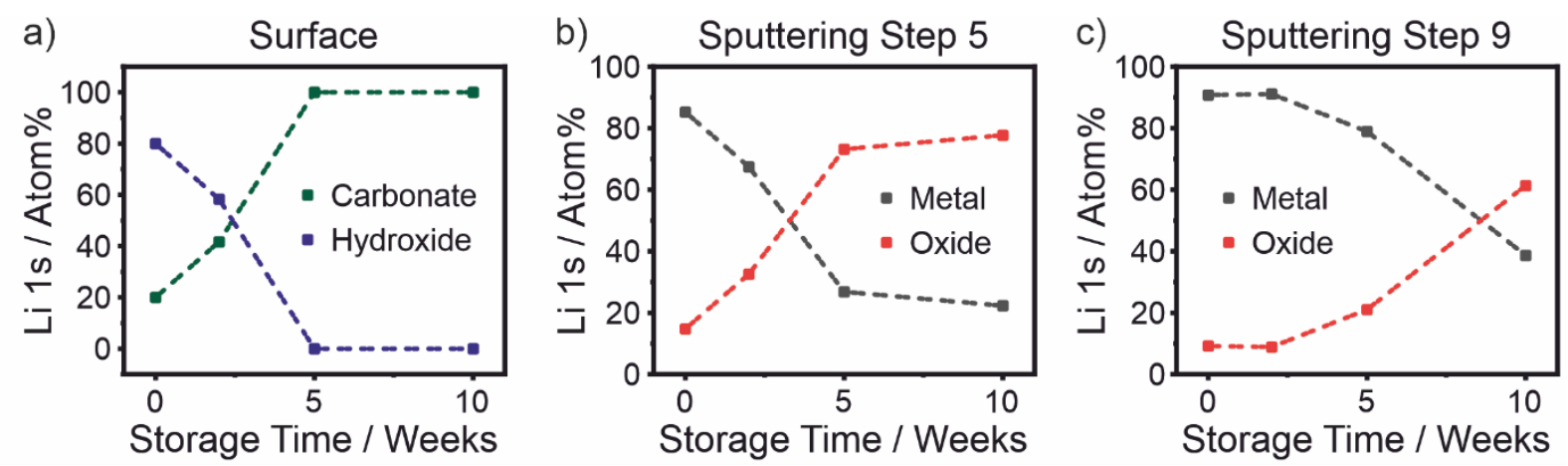

Figure S1: XPS depth profiling. Quantification of the compounds on lithium metal foil stored in glovebox 1 as a function of storage time. a) Carbonate and hydroxide fractions on the sample surfaces (without sputtering) b) $+c$ ) Metal and oxide fractions after sputter steps 5 (sputtering with $1 \mathrm{kV}$ for $3 \mathrm{~min}, 2 \mathrm{kV}$ for 8 min and $4 \mathrm{kV}$ for $15 \mathrm{~min}$ ) and 9 (sputtering with $1 \mathrm{kV}$ for $3 \mathrm{~min}, 2 \mathrm{kV}$ for 8 min and $4 \mathrm{kV}$ for 105 min), respectively. The variances between the samples are differently pronounced for the sputter steps. Sputter step 5 shows the differences most pronounced for 0,2 and 5 weeks, whereas sputter step 9 shows the difference between the foils stored for 5 and 10 weeks. 
a)

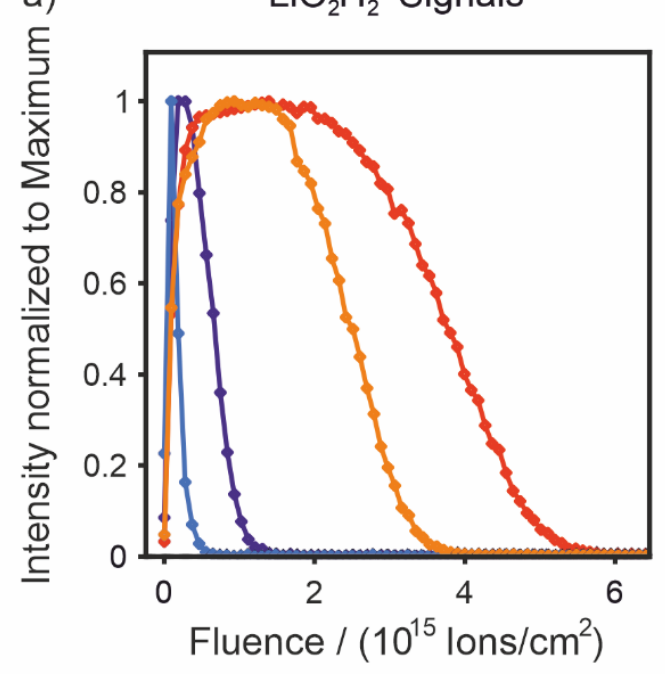

- Box 1 - 2 weeks - Box 1 - 10 weeks

- Box 2 - 2 weeks Box 2 - 10 weeks b) Layer Thicknesses Box 2

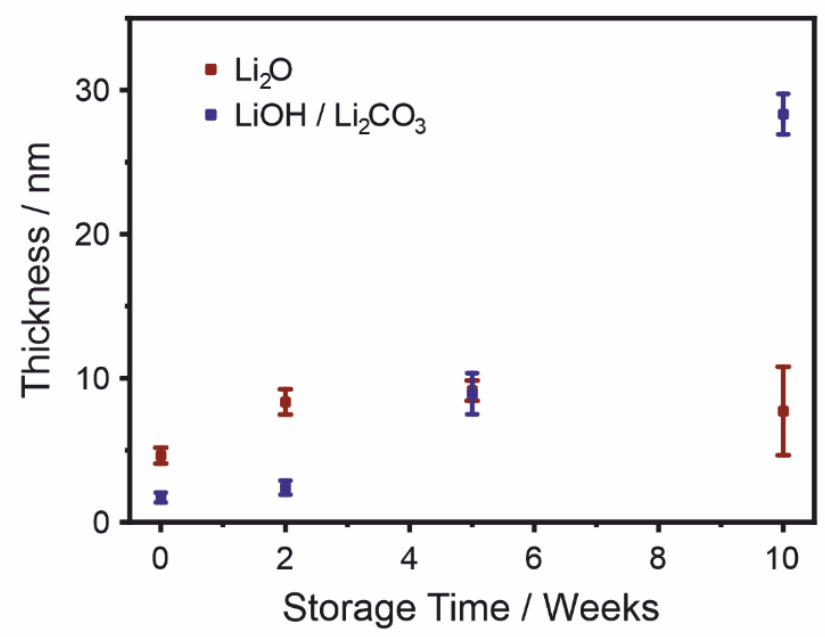

Figure S2: Results from ToF-SIMS depth profiling. a) Comparison of the surface passivation layer of lithium foil stored in glovebox $1\left(\mathrm{p}\left(\mathrm{H}_{2} \mathrm{O}\right.\right.$ and $\left.\mathrm{O}_{2}\right) / \mathrm{p}$ of about $1 \mathrm{ppm}$ and variations up to $\left.10 \mathrm{ppm}\right)$ and

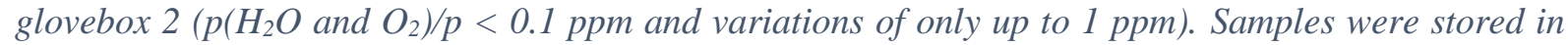
closed plastic boxes. The $\mathrm{LiO}_{2} \mathrm{H}_{2}^{-}$signal of the ToF-SIMS depth profiles is shown as representative for $\mathrm{LiOH}$ to visualize the growth of the passivation layer. b) Quantification of the passivation layer thicknesses on lithium metal foil after storage in closed plastic boxes in glovebox 2 from the ToF-SIMS depth profiles. The trends are similar as in box 1, but less pronounced.

\section{SI 4: Impact of different storage conditions in gloveboxes on lithium foil aging}

a)

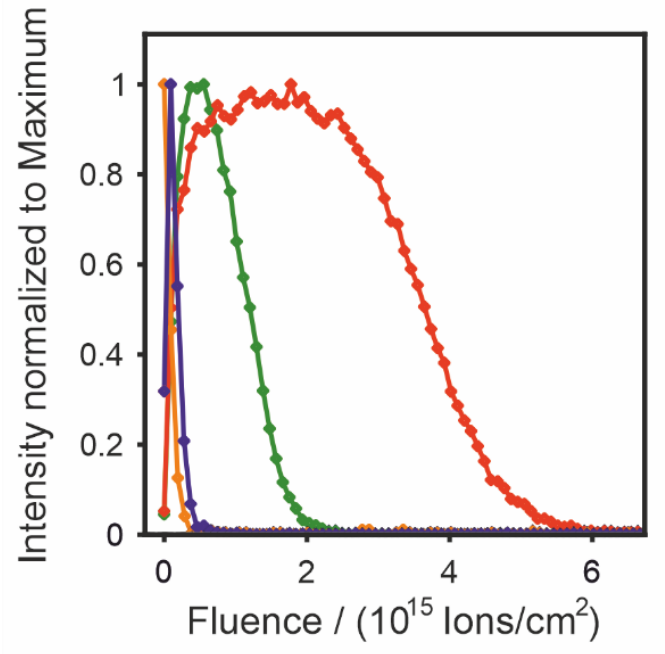

- Reference Box 1 - pouched 5 weeks b)

Layer Thicknesses

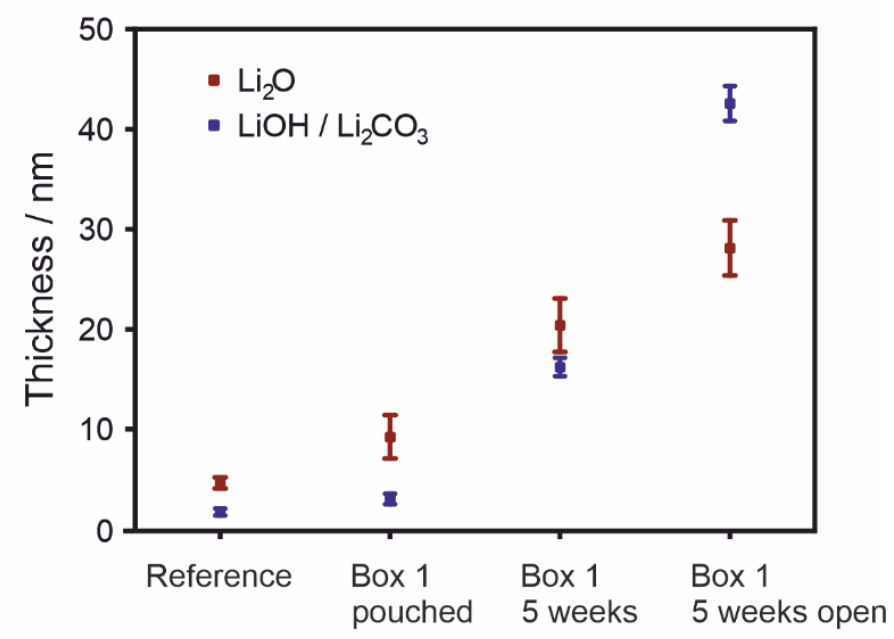

Storage Conditions

- Box 1 - 5 weeks • Box 1 - 5 weeks open

Figure S3: a) Comparison of the surface passivation layer of lithium foil stored in glovebox $1\left(p\left(\mathrm{H}_{2} \mathrm{O}\right.\right.$ and $\left.\mathrm{O}_{2}\right) / \mathrm{p}$ of about $1 \mathrm{ppm}$ and variations up to $10 \mathrm{ppm}$ ) under different conditions. The $\mathrm{LiO}_{2} \mathrm{H}_{2}{ }^{-}$signal 
is shown as representative for $\mathrm{LiOH}$. The reference was taken from an unopened transport package, the Box 1 - pouched sample was stored in a closed plastic box which was additionally sealed in a pouch bag. Sample Box $1-5$ weeks was stored as described before only in a closed plastic box and sample Box 1 - 5 weeks open was put in a box without lid. Samples taken from other unopened transport packages after up to 6 months of storage in gloveboxes showed no significant differences compared to the reference. b) Quantification of the passivation layer thicknesses on lithium metal foil after storage under different conditions in glovebox 1 from the ToF-SIMS depth profiles. The sample which was protected by an additional pouch bag shows only minor passivation layer growth. Open storage increases the growth of the passivation layer importantly.

\section{SI 5: Ideal lithium electrodes}

The concept of "ideal" lithium electrodes ( $\mathrm{Li}_{\mathrm{id}}$ ) for LLZO solid electrolyte was introduced by Krauskopf et al. in 2019. ${ }^{1}$ They showed that the interfacial resistance between LLZO and lithium becomes practically $0 \Omega \cdot \mathrm{cm}^{2}$ after isostatic pressing at high external pressure of several $100 \mathrm{MPa}$ and remains low. Consequently, only LLZO bulk and grain boundary (GB) contributions are measured for an ideal lithium electrode, as shown by the Nyquist plot in Figure S4. The authors showed that the contact geometry and the ionic transport in the LLZO control the interfacial contributions for a clean interface in equilibrium and they validated their findings with microelectrode studies. ${ }^{2}$ Observed interface contributions can therefore be attributed to constriction resistances, which originate from insufficient contact through pores or passivation layers.

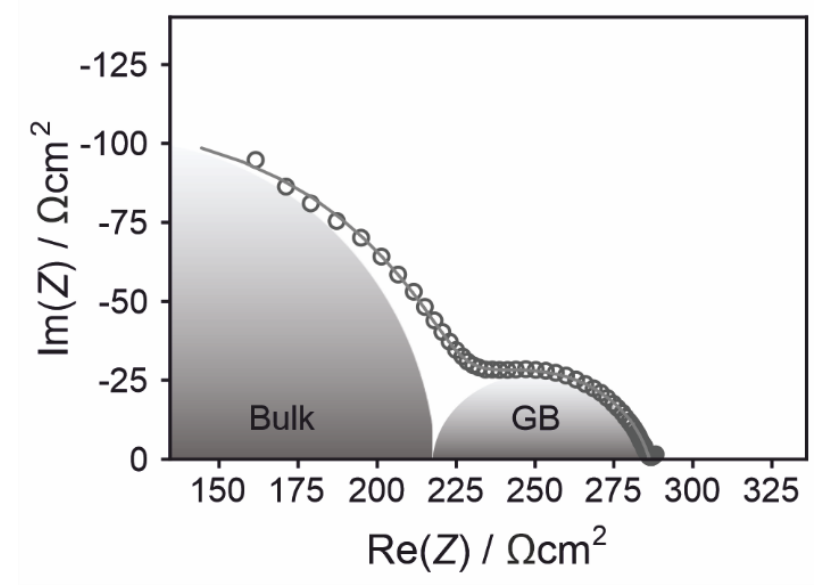

Figure S4: Nyquist plot for $L i_{i d}|L L Z O| L i_{i d .}$. Only bulk and grain boundary, but no interface contributions, are present. 


\section{SI 6: Representative Nyquist plots}

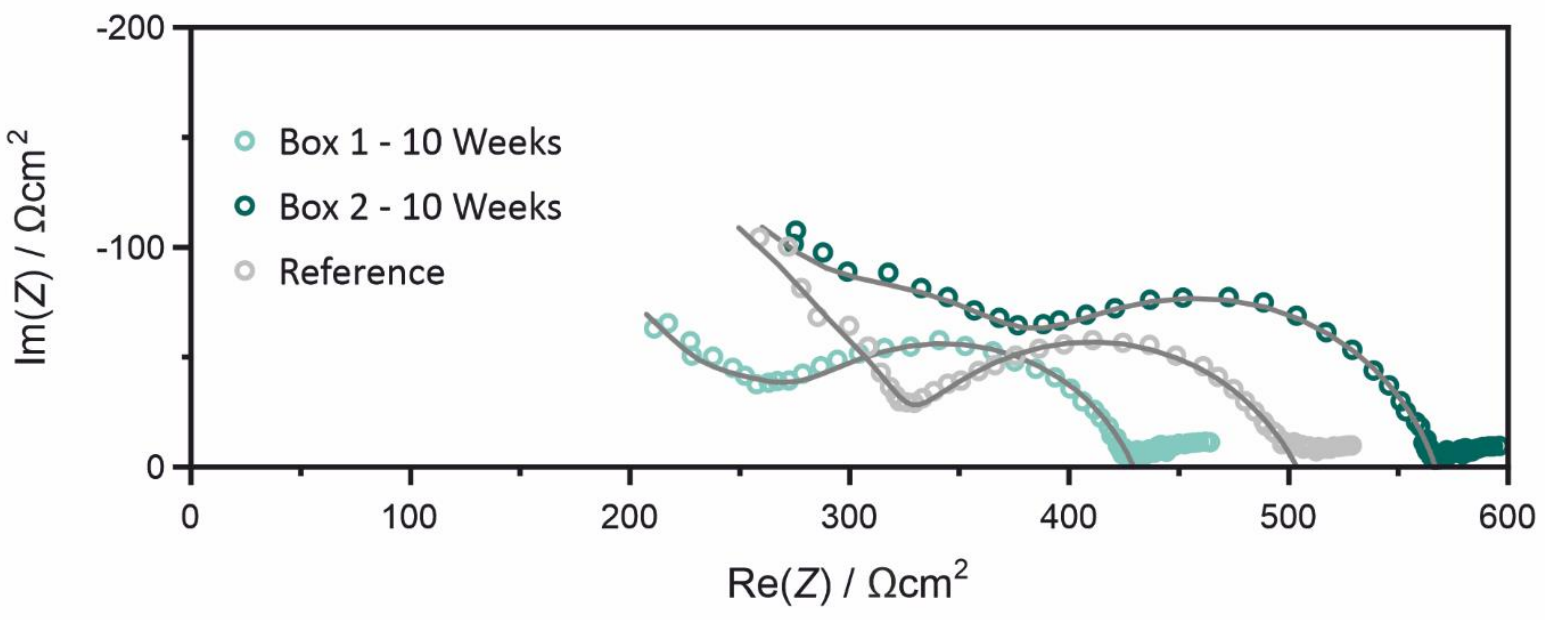

Figure S5: Exemplary Nyquist plots which were used to determine the interface resistances of Li|LLZO for the stored lithium foil samples. The measurements for lithium foil stored for 10 weeks in glovebox 1 $\left(p\left(\mathrm{H}_{2} \mathrm{O}\right.\right.$ and $\left.\mathrm{O}_{2}\right) / p$ of about $1 \mathrm{ppm}$ and variations up to $\left.10 \mathrm{ppm}\right)$ or glovebox $2\left(\mathrm{p}\left(\mathrm{H}_{2} \mathrm{O}\right.\right.$ and $\left.\mathrm{O}_{2}\right) / \mathrm{p}<0.1$ ppm and variations of only up to $1 \mathrm{ppm}$ ) are shown in comparison to the measurement for a reference lithium foil which was taken from an unopened transport package. The interface contributions are similar for all samples.

\section{SI 7: Cryo FIB-SEM for interface visualization}

Cryo focussed ion beam scanning electron microscopy (FIB-SEM) measurements were performed with a XEIA3 GMU SEM/Plasma-FIB (Tescan) instrument in combination with a Leica VCT500 transfer module and a liquid nitrogen cooling stage $\left(-130{ }^{\circ} \mathrm{C}\right)$. As samples, lithium foil with an overall passivation layer thickness of about $100 \mathrm{~nm}$ was pressed with a preparation pressure of 40 or $400 \mathrm{MPa}$ to LLZO polished with P1000. On the FIB crater walls, the interface between lithium and LLZO was investigated with SEM (measured at $3 \mathrm{kV}$, SE in beam detector). For a preparation pressure of $40 \mathrm{MPa}$ (Figure S6a), pores are present at the interface. In contrast, the lithium fills every void of the solid electrolyte for a preparation pressure of $400 \mathrm{MPa}$ (Figure S6b). The passivation layer of the lithium foil could not be identified definitely due to edge effects at the interfaces as well as limited morphological and topological contrast. 

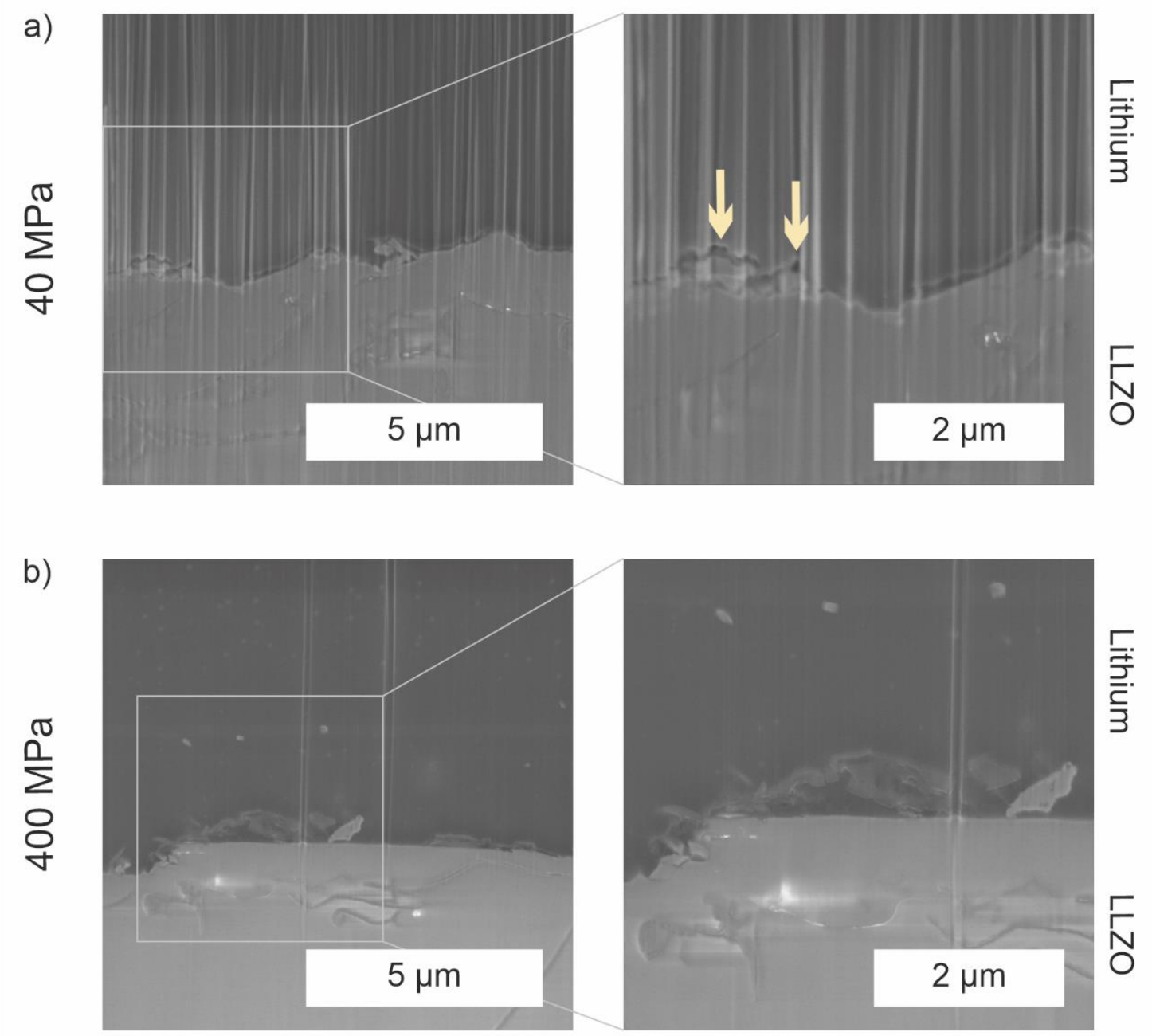

Figure S6: Cryo FIB-SEM SE images of Li|LLZO interfaces. LLZO pellets were polished with P1000 to an average roughness of about $160 \mathrm{~nm}$ including a maximal variation of $1.9 \mu \mathrm{m}$ in height. The overall thickness of the lithium passivation layer was about $100 \mathrm{~nm}$. For a preparation pressure of $40 \mathrm{MPa}(\mathrm{a})$, pores are visible at the interface (arrows) whereas a preparation pressure of $400 \mathrm{MPa}(b)$ led to a close contact between lithium and solid electrolyte.

\section{SI 8: Theory about the reactivity of lithium toward atmospheric gases}

In 2016, Schiemann et al. published a review on lithium combustion, in which the authors also discuss the main findings about the reaction of the atmospheric gases with lithium. ${ }^{3}$ They conclude that the reaction of lithium with dry oxygen, nitrogen and carbon dioxide is negligible at room temperature. This is in accordance with a theoretical study by Shang et al. who claim that the reaction between lithium and the three named pure gases cannot occur at ambient temperature. ${ }^{4}$ Also, the fact that lithium metal can be handled in dry-rooms where only $p\left(\mathrm{H}_{2} \mathrm{O}\right)$ is reduced to a minimum, supports a limited reactivity toward the other air components. However, both authors highlight that the reactivity largely depends on the surface state of lithium. According to Shang et al., the reaction between lithium and water can enable the reaction with other gases via the reaction products $\mathrm{LiH}$ and $\mathrm{LiOH} .{ }^{4}$ Schiemann et al. emphasize that the reaction of lithium is very sensitive to the presence of impurities like water in the reaction gas or already existing $\mathrm{LiOH}$ or $\mathrm{Li}_{3} \mathrm{~N}$ on the lithium surface. ${ }^{3}$ Still, there are also recent reports about the interaction of pure lithium metal and dry atmospheric gases which claim an intrinsic interaction. Etxebarria et al. combined XPS, UPS and DFT to characterize the interaction of $\mathrm{O}_{2}, \mathrm{CO}_{2}$ and $\mathrm{N}_{2}$ with clean lithium surfaces and found oxidation of lithium metal by $\mathrm{O}_{2}$ and $\mathrm{CO}_{2} \cdot \mathrm{N}_{2}$ showed no reactivity 
with clean lithium metal. However, also these authors stress that traces of impurities have a major impact on the reactivity of lithium surfaces and strongly influence the obtained results. ${ }^{5}$

\section{SI 9: Pilling-Bedworth ratio}

Pilling and Bedworth found that it depends on the relative molar volume of a metal and the corresponding metal oxide if the metal oxide can form a covering and protective layer on the metal. ${ }^{6,7}$ To classify different metal oxides, the Pilling-Bedworth ratio is calculated as follows:

$$
\mathrm{PBR}=\frac{V_{\text {Oxide }}}{n \cdot V_{\text {Metal }}}=\frac{M_{\text {Oxide }} \cdot \rho_{\text {Metal }}}{n \cdot M_{\text {Metal }} \cdot \rho_{\text {Oxide }}}
$$

$V_{\mathrm{x}}$ : molar volume of $\mathrm{x}$

$n$ : number of metal atoms in the formula of the oxide

$M_{\mathrm{x}}:$ molar mass of $\mathrm{x}$

$\rho_{\mathrm{x}}:$ density of $\mathrm{x}$

For a ratio smaller than one, the oxide film is unprotective, as it will be porous and/or cracked. Consequently, the oxidation reaction is not self-limiting and the thickness of the oxide film will increase steadily. For ratios between one and two, a covering and protective film forms, whereas a ratio larger than two will again lead to cracking and therefore to an unprotective film.

The PBR can also be used to estimate, if products other than oxides may form covering films on a metal. In this context, the ratios are no irrevocable proof or fixed limit. However, values which are much smaller than 1 or importantly larger than 2, give a valid basis to explain an on-going reaction. Also, values which lie between 1 and 2 indicate the formation of a covering and protective reaction layer.

In Table S3 the PBRs for selected lithium compounds on lithium metal are given. The ratios for $\mathrm{Li}_{2} \mathrm{CO}_{3}$ and $\mathrm{LiOH}$ are between 1 and 2, what indicated the formation of a covering film on lithium metal. For $\mathrm{Li}_{3} \mathrm{~N}$, the ratio is importantly smaller than one what may explain the on-going reaction of lithium metal with $\mathrm{N}_{2}$.

Table S3: Pilling-Bedworth ratio for lithium compounds on lithium metal. Ratios smaller than one indicate the formation of a porous and/or cracked film. Ratios between one and two direct the formation of a covering and protective film.

\begin{tabular}{|l|l|l|l|l|l|l|}
\hline Compound & $\mathrm{Li}_{2} \mathrm{CO}_{3}$ & $\mathrm{Li}_{2} \mathrm{O}$ & $\mathrm{LiOH}$ & $\mathrm{LiH}$ & $\mathrm{Li}_{2} \mathrm{O}_{2}$ & $\mathrm{Li}_{3} \mathrm{~N}$ \\
\hline PBR & 1.35 & 0.57 & 1.26 & 0.78 & 0.75 & 0.69 \\
\hline
\end{tabular}




\section{SI 10: Photo of stored lithium foil}

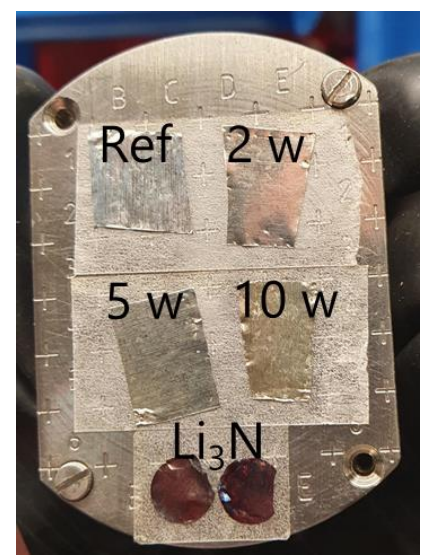

Figure S7: Photograph of lithium foil samples after storage in glovebox 1. The larger lithium foil pieces showed a color change from metallic towards yellowish-brown for storage of up to 10 weeks. Some samples, here the two punched out samples at the bottom of the picture, tarnished and became brittle during storage due to $\mathrm{Li}_{3} \mathrm{~N}$ formation.

\section{SI 11: Reactivity of unprotected lithium surfaces toward atmospheric gases}

To investigate the reactivity of lithium without protective passivation layer, fresh lithium surfaces were exposed to pure atmospheric gases. The samples were cut directly in the gas stream to prevent undefined sample changes before the actual reaction. Results from XPS and ToF-SIMS characterization of the samples are shown in Figure S6. For exposure to $\mathrm{CO}_{2}$ and $\mathrm{O}_{2}$ only thin reaction layers formed and after sputtering lithium metal was detected by XPS. This was not possible for the samples exposed to $\mathrm{N}_{2}$ or $\mathrm{H}_{2} \mathrm{O}$. For these two samples, only reaction products were accessible, what indicates the formation of thick reaction layers. 
XPS

a)

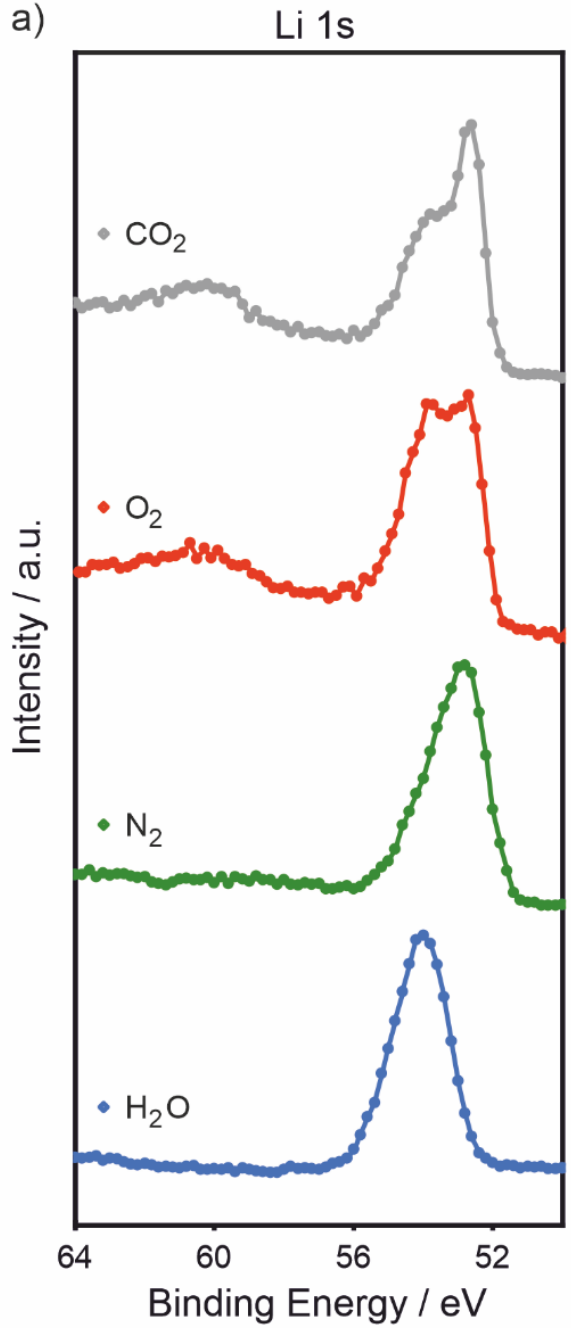

ToF-SIMS

b)

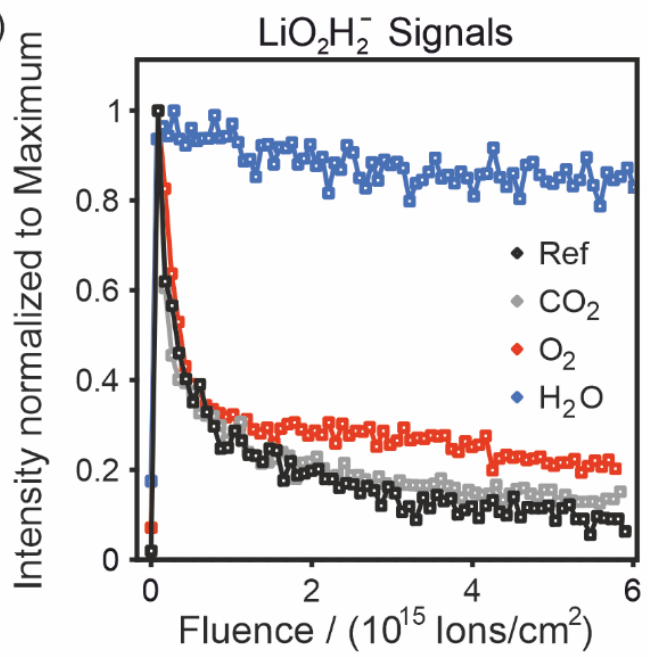

c)

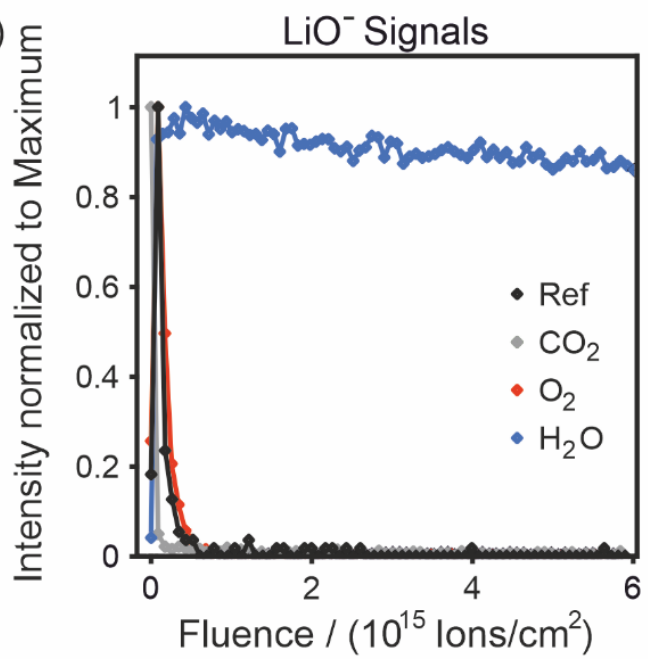

Figure S8: Reaction of fresh lithium surfaces with the atmosphere gases $\mathrm{O}_{2}, \mathrm{CO}_{2}, \mathrm{~N}_{2}$ and $\mathrm{H}_{2} \mathrm{O}(\mathrm{Ar}$ as carrier gas). a) XP spectra of the Li $1 \mathrm{~s}$ region after sputter step 6 (sputtering with $1 \mathrm{kV}$ for 3 min, $2 \mathrm{kV}$ for 8 min and $4 \mathrm{kV}$ for $30 \mathrm{~min}$ ). For exposure to $\mathrm{CO}_{2}$ and $\mathrm{O}_{2}$, the plasmon-loss features show the presence of lithium metal. For exposure to $\mathrm{N}_{2}$, no plasmon-loss features are observed and the shift of the signal to low binding energies indicates the presence of $\mathrm{Li}_{3} \mathrm{~N}$. Accordingly, signals are observed in the $\mathrm{N} 1 \mathrm{~s}$ region. After reaction with water the signal only shows the presence of $\mathrm{LiOH}$ and $\left.\mathrm{Li}_{2} \mathrm{O} . b\right)+c$ ) $\mathrm{ToF}$ SIMS depth profiles after reaction showing the $\mathrm{LiOH}$ and $\mathrm{Li}_{2} \mathrm{O}$ rich regions respectively. Only for exposure to water pronounced differences compared to the reference sample were observed.

\section{SI 12: Reactivity of unprotected lithium surfaces in gloveboxes with and without nitrogen filter}

A sliced sample of lithium was prepared and stored in a closed plastic box in glovebox 1 . Within only 5 weeks, the about $3 \mathrm{~mm}$ thick slice of lithium became completely brownish-red and brittle. With XPS, the formation of $\mathrm{Li}_{3} \mathrm{~N}$ could be confirmed as shown in Figure S7. For comparison, a slice of lithium was stored in a glovebox with additional $\mathrm{N}_{2}$ filter (glovebox 3), where the $\mathrm{N}_{2}$ partial pressure fraction was within the 5 weeks of storage always around $1 \mathrm{ppm}$. For this sample, no $\mathrm{Li}_{3} \mathrm{~N}$ was detected by XPS and lithium metal was identified after sputtering by the plasmon-loss features at around $60 \mathrm{eV}$. 
a)

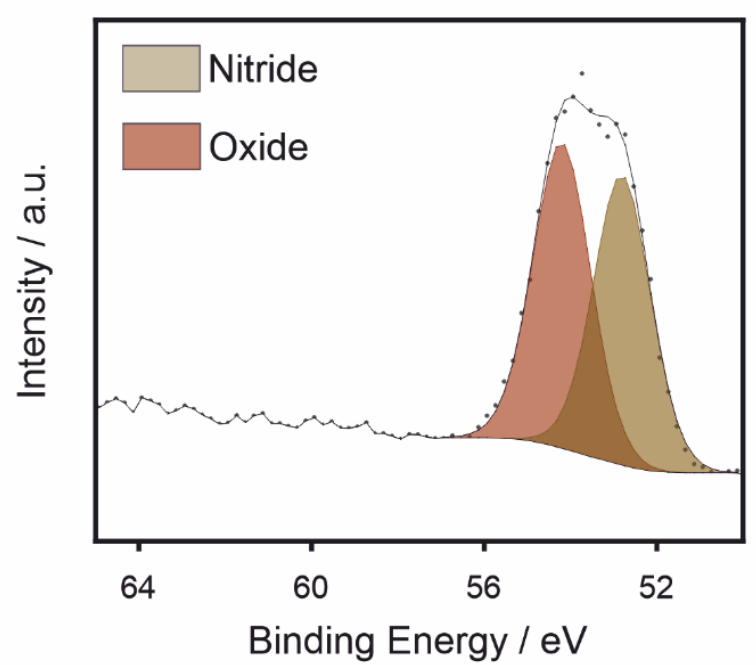

b) With Nitrogen Filter

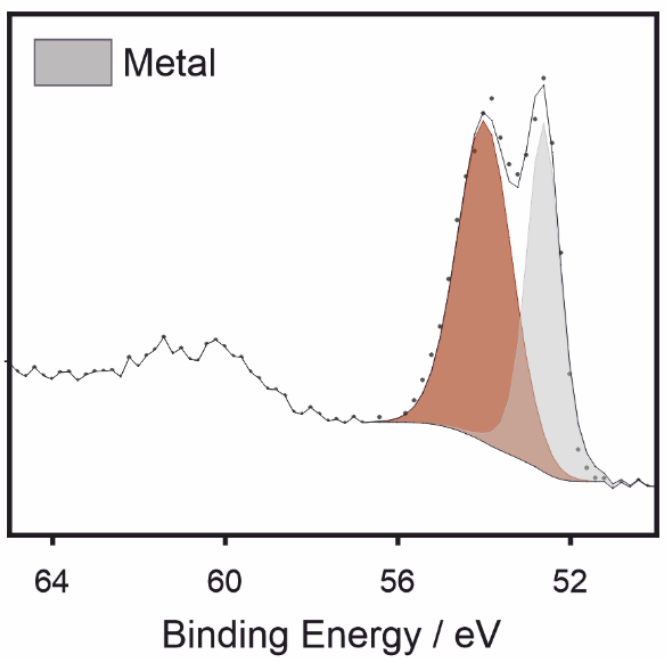

Figure S9: XP spectra of fresh lithium surfaces stored in gloveboxes without and with nitrogen filter. $X P$ spectra of the Li 1 s region for sputter step 6 (sputtering with $1 \mathrm{kV}$ for $3 \mathrm{~min}, 2 \mathrm{kV}$ for 8 min and $4 \mathrm{kV}$ for $30 \mathrm{~min}$ ) are shown. a) Without nitrogen filter, no plasmon-loss features are observed and the shift of the signal to low binding energies indicates the presence of Li $i_{3} N$. Accordingly, signals are observed in the $N$ ls region. b) With nitrogen filter, the plasmons-loss features show the presence of lithium metal, what indicates that only a comparably thin reaction layer formed.

\section{References}

(1) Krauskopf, T.; Hartmann, H.; Zeier, W. G.; Janek, J. Toward a Fundamental Understanding of the Lithium Metal Anode in Solid-State Batteries-An Electrochemo-Mechanical Study on the Garnet-Type Solid Electrolyte Li6.25A10.25La3Zr2O12. ACS applied materials \& interfaces 2019, 11 (15), 14463-14477. DOI: $10.1021 /$ acsami.9b02537.

(2) Krauskopf, T.; Mogwitz, B.; Hartmann, H.; Singh, D. K.; Zeier, W. G.; Janek, J. The Fast Charge Transfer Kinetics of the Lithium Metal Anode on the Garnet-Type Solid Electrolyte Li 6.25 Al 0.25 La 3 Zr 2 O 12. Adv. Energy Mater. 2020, 10 (27), 2000945. DOI: 10.1002/aenm.202000945.

(3) Schiemann, M.; Bergthorson, J.; Fischer, P.; Scherer, V.; Taroata, D.; Schmid, G. A review on lithium combustion. Applied Energy 2016, 162, 948-965. DOI: 10.1016/j.apenergy.2015.10.172.

(4) Shang, J.; Shirazian, S. Facilitated Dissociation of Water in the Presence of Lithium Metal at Ambient Temperature as a Requisite for Lithium-Gas Reactions. J. Phys. Chem. C 2018, 122 (28), 16016-16022. DOI: 10.1021/acs.jpcc.8b01817.

(5) Etxebarria, A.; Koch, S. L.; Bondarchuk, O.; Passerini, S.; Teobaldi, G.; Muñoz-Márquez, M. Á. Work Function Evolution in Li Anode Processing. Adv. Energy Mater. 2020, 10 (24), 2000520. DOI: 10.1002/aenm.202000520.

(6) Hart, C. A.; Skinner, C. H.; Capece, A. M.; Koel, B. E. Sorption of atmospheric gases by bulk lithium metal. Journal of Nuclear Materials 2016, 468, 71-77. DOI: 10.1016/j.jnucmat.2015.11.006.

(7) Pilling, N. B. The Oxidation of Metals at High Temperature. J. Inst. Met. 1923, 29, 529-582. 